\title{
Assessment of Cardiac Remodeling-A Chance for Novel Cardiac Biomarkers?
}

\author{
Peter Jirak, Moritz Mirna ${ }^{\circledR}$, Bernhard Wernly $₫$, Vera Paar, Uta C. Hoppe \\ and Michael Lichtenauer *(D) \\ Department of Internal Medicine II, Division of Cardiology, Paracelsus Medical University Salzburg, \\ 5020 Salzburg, Austria; p.jirak@salk.at (P.J.); m.mirna@salk.at (M.M.); b.wernly@salk.at (B.W.); \\ v.paar@salk.at (V.P.); u.hoppe@salk.at (U.C.H.) \\ * Correspondence: m.lichtenauer@salk.at; Tel.: +43-57855-57130
}

Received: 21 June 2020; Accepted: 29 June 2020; Published: 3 July 2020

\section{Background}

Biomarkers are defined as "cellular, biochemical or molecular alterations that are measurable in biological media such as human tissues, cells, or fluids", providing "biological characteristics that can be objectively measured and evaluated as an indicator of normal biological processes, pathogenic processes, or pharmacological responses to a therapeutic intervention "according to Hulka et al. as well as Naylor et al. [1,2]. Depending on their respective role in physiologic and pathophysiologic processes, biomarkers can be used for different purposes such as disease diagnosis, risk stratification, screening, as well as prognosis [2]. In recent decades, biomarkers have gained major clinical significance, especially in the cardiovascular field. Above all, the introduction of natriuretic peptides and highly sensitive troponin assays have led to significant facilitation and improvement in clinical practice.

However, while these markers represent indispensable diagnostic tools in clinical routines, their prognostic impact remains limited. Accordingly, the evaluation of prognosis remains a clinical challenge, even to date. In contrast to the aforementioned markers, novel biomarkers targeting the critical factors for prognosis and outcomes in cardiovascular disease, cardiac fibrosis, and remodeling could be of additional value on this account $[3,4]$. Cardiac remodeling: The term cardiac remodeling describes changes in the size; mass; geometry; and, consequently, function of the heart in response to acute and chronic myocardial damage [5]. While acute myocardial damage is usually induced by ischemic processes such as myocardial infarction, chronic damage comprises inflammatory processes, dysregulated metabolic pathways, toxic damage, as well as a chronic increase in cardiac strain [6-8].

Interestingly, in contrast to natriuretic peptides as well as troponin, most novel heart failure biomarkers do not provide a comparable amount of organ specificity $[9,10]$. However, due to their involvement in multiple pathophysiologic processes, novel cardiac biomarkers represent promising tools to refine the assessment of cardiac remodeling and fibrosis and thus also of prognosis [4,11].

\section{2. sST2}

The most promising marker on this regard represents soluble suppression of tumorigenicity 2 (sST2), which has also found entrance into current guidelines to some extent. sST2 represents a versatile marker, predominantly used in heart failure patients [12]. SST2 was shown to be elevated in acute and chronic heart failure as well as in acute coronary syndrome $[13,14]$. Besides, elevated levels have also been reported in pulmonary hypertension and peripheral artery disease, emphasizing its involvement in different disease entities $[15,16]$.

Regarding its molecular background, two different isoforms have been identified, a soluble form (sST2) and a membrane-bound form (ST2L) [17]. Interleukin-33 (IL-33) represents the only known ligand for ST2 and is responsible for the induction of cardioprotective effects by binding to the ST2L 
receptor [17]. Besides, IL-33 is also involved in immunomodulation through the secretion and the interaction of T helper 2 (TH2) cells, mast cells, group 2 innate lymphoid cells, (ILC2s) regulatory T (Treg) cells, TH1 cells, CD8+ T cells, and natural killer (NK) cells, among others, further elucidating the involvement of sST2 and ST2L in inflammatory processes [18]. On the other hand, sST2 can counteract the cardioprotective effects by acting as a decoy receptor for IL-33 [17]. Hence, an increase in SST2 results in a decrease of cardioprotective IL-33, consequently leading to cardiac damage and increased cardiac strain [17].

In short, sST2 incorporates different pathophysiological processes involved in cardiac remodeling and fibrosis such as inflammation and increased cardiac strain. Accordingly, sST2 represents a promising new marker in the assessment of prognosis of heart failure patients. SST2 was shown to predict all-cause mortality as well as cardiovascular mortality in chronic heart failure patients [19]. Additionally, sST2 was reported to predict mortality in acute heart failure [11]. With regards to therapy monitoring, an SST2 cut-off below 35-ng/mL was proposed to significantly improve outcomes in heart failure patients (Pres-ageassay, Critical Diagnostics, SanDiego, California, USA) [19].

\section{3. microRNAs}

While sST2 has already found entrance into current guidelines, the field of microRNAs (miRNAs) is currently limited to investigative research, although previous trials have reported promising results regarding their diagnostic and therapeutic applicability in cardiovascular disease entities. MiRNAs comprise a group of small (19-24 nucleotides) ribonucleic acids (RNAs), which play a pivotal role in posttranslational gene silencing (PTGS) and hence regulation of protein synthesis $[20,21]$. In recent studies, several miRNAs were found to be involved in cardiac remodeling by promoting myocardial inflammation, as well as pro-fibrotic and -apoptotic pathways. Consequently, patients with acute and chronic heart failure show dysregulated plasma concentrations of various pathological miRNAs, which gives rise to novel diagnostic approaches in these patients. For example, Ovchinnikova et al. recently identified several significantly dysregulated miRNAs (miR-18a-5p, miR-26b-5p, miR-27a-3p, miR-30e-5p, miR-106a-5p, miR-199a-3p, and miR-652-3p) in acute heart failure (AHF), which were also associated with adverse outcomes in these patients [22]. Furthermore, another trial reported that a combination of miR-30c, miR-221, miR-328, and miR-375 could adequately discriminate heart failure with preserved ejection fraction (HFpEF) from heart failure with reduced ejection fraction (HFrEF) [23], which is to this extent not possible using conventional cardiovascular biomarkers [24]. Consequently, analysis of the miRNA expression pattern ("miRNome") could provide substantial additional information in the clinical management of patients with HF in the future.

Besides their application in diagnostics, miRNAs also constitute interesting targets for novel therapeutic approaches. Since myocardial inflammation and cardiac fibrosis are considered potentially reversible processes in the course of cardiac remodeling, miRNAs interacting with these pathways represent promising targets in the management of patients with HF. For example, miR-21 was found to enhance myocardial fibrosis by targeting the extracellular signal-regulated kinase (ERK)-mitogen-activated protein (MAP) kinase pathway, and silencing of miR-21 by synthetic antagonist significantly attenuated myocardial fibrosis in an animal model [25]. Since miR-21 was also found to be involved in myocardial inflammation by targeting T-cell development, it constitutes an interesting drug target in the management of HF and certainly warrants further investigation in future studies.

\section{Conclusions}

Despite the long time period since the establishment of natriuretic peptides and troponin in clinical practice, the evaluation of prognosis in cardiovascular disease remains challenging. The assessment of cardiac remodeling and fibrosis with the help of novel biomarkers represents a promising approach for a more sophisticated evaluation of prognosis and consequently also therapy guiding. In this regard, their versatility regarding their involvement in numerous different organ systems might be a considerable 
benefit over natriuretic peptides and troponin with regards to their prognostic value. As cardiac remodeling is strongly correlated with a worse prognosis in cardiovascular disease, the implementation of biomarkers addressing this issue holds great potential to improve outcomes further.

Funding: This research received no external funding.

Conflicts of Interest: The authors declare no conflict of interest.

\section{References}

1. Hulka, B.S.; Wilcosky, T.C.; Griffith, J.D.; Rynard, S.M. Biological markers in epidemiology. Am. J. Hum. Biol. 1990, 3 .

2. Naylor, S. Biomarkers: Current perspectives and future prospects. Expert Rev. Mol. Diagn. 2003, 3, 525-529. [CrossRef]

3. Lichtenauer, M.; Jirak, P.; Wernly, B.; Paar, V.; Rohm, I.; Jung, C.; Schernthaner, C.; Kraus, J.; Motloch, L.J.; Yilmaz, A.; et al. A comparative analysis of novel cardiovascular biomarkers in patients with chronic heart failure. Eur. J. Intern. Med. 2017, 44, 31-38. [CrossRef]

4. Zagidullin, N.; Motloch, L.J.; Gareeva, D.; Hamitova, A.; Lakman, I.; Krioni, I.; Popov, D.; Zulkarneev, R.; Paar, V.; Kopp, K.; et al. Combining Novel Biomarkers for Risk Stratification of Two-Year Cardiovascular Mortality in Patients with ST-Elevation Myocardial Infarction. J. Clin. Med. 2020, 9, 550. [CrossRef] [PubMed]

5. Azevedo, P.S.; Polegato, B.F.; Minicucci, M.F.; Paiva, S.A.; Zornoff, L.A. Cardiac Remodeling: Concepts, Clinical Impact, Pathophysiological Mechanisms and Pharmacologic Treatment. Arq. Bras. Cardiol. 2016, 106, 62-69. [CrossRef]

6. Talman, V.; Ruskoaho, H. Cardiac fibrosis in myocardial infarction-from repair and remodeling to regeneration. Cell Tissue Res. 2016, 365, 563-581. [CrossRef] [PubMed]

7. Li, L.; Zhao, Q.; Kong, W. Extracellular matrix remodeling and cardiac fibrosis. Matrix Biol. 2018, 69, 490-506. [CrossRef]

8. Nakamura, M.; Sadoshima, J. Mechanisms of physiological and pathological cardiac hypertrophy. Nat. Rev. Cardiol. 2018, 15, 387-407. [CrossRef]

9. Savic-Radojevic, A.; Pljesa-Ercegovac, M.; Matic, M.; Simic, D.; Radovanovic, S.; Simic, T. Novel Biomarkers of Heart Failure. Adv. Clin. Chem. 2017, 79, 93-152.

10. Correale, M.; Monaco, I.; Brunetti, N.D.; Di Biase, M.; Metra, M.; Nodari, S.; Butler, J.; Gheorghiade, M. Redefining biomarkers in heart failure. Heart Fail. Rev. 2018, 23, 237-253. [CrossRef]

11. Aimo, A.; Januzzi, J.L., Jr.; Bayes-Genis, A.; Vergaro, G.; Sciarrone, P.; Passino, C.; Emdin, M. Clinical and Prognostic Significance of sST2 in Heart Failure: JACC Review Topic of the Week. J. Am. Coll. Cardiol. 2019, 74, 2193-2203. [CrossRef] [PubMed]

12. McCarthy, C.P.; Januzzi, J.L., Jr. Soluble ST2 in Heart Failure. Heart Fail. Clin. 2018, 14, 41-48. [CrossRef] [PubMed]

13. Jenkins, W.S.; Roger, V.L.; Jaffe, A.S.; Weston, S.A.; AbouEzzeddine, O.F.; Jiang, R.; Manemann, S.M.; Enriquez-Sarano, M. Prognostic Value of Soluble ST2 After Myocardial Infarction: A Community Perspective. Am. J. Med. 2017, 130, 23. [CrossRef]

14. Pascual-Figal, D.A.; Lax, A.; Perez-Martinez, M.T.; del Carmen Asensio-Lopez, M.; Sanchez-Mas, J. Clinical relevance of sST2 in cardiac diseases. Clin. Chem. Lab. Med. 2016, 54, 29-35. [CrossRef] [PubMed]

15. Jirak, P.; Mirna, M.; Wernly, B.; Paar, V.; Thieme, M.; Betge, S.; Franz, M.; Hoppe, U.; Lauten, A.; Kammler, J.; et al. Analysis of novel cardiovascular biomarkers in patients with peripheral artery disease (PAD). Minerva Med. 2018, 109, 443. [CrossRef]

16. Mirna, M.; Rohm, I.; Jirak, P.; Wernly, B.; Baz, L.; Paar, V.; Kretzschmar, D.; Hoppe, U.C.; Schulze, P.C.; Lichtenauer, M.; et al. Analysis of Novel Cardiovascular Biomarkers in Patients with Pulmonary Hypertension (PH). Heart Lung Circ. 2020, 29, 337-344. [CrossRef]

17. Kakkar, R.; Lee, R.T. The IL-33/ST2 pathway: Therapeutic target and novel biomarker. Nat. Rev. Drug Discov. 2008, 7, 827-840. [CrossRef]

18. Cayrol, C.; Girard, J.P. Interleukin-33 (IL-33): A nuclear cytokine from the IL-1 family. Immunol. Rev. 2018, 281, 154-168. [CrossRef] 
19. Aimo, A.; Vergaro, G.; Passino, C.; Ripoli, A.; Ky, B.; Miller, W.L.; Bayes-Genis, A.; Anand, I.; Januzzi, J.L.; Emdin, M. Prognostic Value of Soluble Suppression of Tumorigenicity-2 in Chronic Heart Failure: A Meta-Analysis. JACC Heart Fail. 2017, 5, 280-286. [CrossRef]

20. Kim, S.; Song, M.L.; Min, H.; Hwang, I.; Baek, S.K.; Kwon, T.K.; Park, J.W. miRNA biogenesis-associated RNase III nucleases Drosha and Dicer are upregulated in colorectal adenocarcinoma. Oncol. Lett. 2017, 14, 4379-4383. [CrossRef]

21. Mohr, A.M.; Mott, J.L. Overview of microRNA biology. Semin. Liver Dis. 2015, 35, 3-11. [CrossRef] [PubMed]

22. Ovchinnikova, E.S.; Schmitter, D.; Vegter, E.L.; Ter Maaten, J.M.; Valente, M.A.; Liu, L.C.; van der Harst, P.; Pinto, Y.M.; de Boer, R.A.; Meyer, S.; et al. Signature of circulating microRNAs in patients with acute heart failure. Eur. J. Heart Fail. 2016, 18, 414-423. [CrossRef] [PubMed]

23. Watson, C.J.; Gupta, S.K.; O'Connell, E.; Thum, S.; Glezeva, N.; Fendrich, J.; Gallagher, J.; Ledwidge, M.; Grote-Levi, L.; McDonald, K.; et al. MicroRNA signatures differentiate preserved from reduced ejection fraction heart failure. Eur. J. Heart Fail. 2015, 17, 405-415. [CrossRef] [PubMed]

24. Jirak, P.; Pistulli, R.; Lichtenauer, M.; Wernly, B.; Paar, V.; Motloch, L.J.; Rezar, R.; Jung, C.; Hoppe, U.C.; Schulze, P.C.; et al. Expression of the Novel Cardiac Biomarkers sST2, GDF-15, suPAR, and H-FABP in HFpEF Patients Compared to ICM, DCM, and Controls. J. Clin. Med. 2020, 9, 1130. [CrossRef] [PubMed]

25. Thum, T.; Gross, C.; Fiedler, J.; Fischer, T.; Kissler, S.; Bussen, M.; Galuppo, P.; Just, S.; Rottbauer, W.; Frantz, S.; et al. MicroRNA-21 contributes to myocardial disease by stimulating MAP kinase signalling in fibroblasts. Nature 2008, 456, 980-984. [CrossRef] [PubMed]

(C) 2020 by the authors. Licensee MDPI, Basel, Switzerland. This article is an open access article distributed under the terms and conditions of the Creative Commons Attribution (CC BY) license (http://creativecommons.org/licenses/by/4.0/). 